
analizom mikrovoltažne promjenljivosti izoelektričnih segmenata snimljenih triaksijalnim elektrokardiografom visoke rezolucije - odstupanja u ovisnosti o dobi i spolu

\title{
Characteristics of diastolic function of healthy subjects analyzed by microvoltage variability of isoelectric segments, recorded by three-axial high resolution electrocardiograph device - deviations depending on age and gender
}

Vedrana Baraban', Srđan Čalošević Sven Kurbel', Svjetlana Marić ${ }^{3}$

'Medicinski fakultet Sveučilišta u Osijeku, Klinički bolnički centar Osijek, Osijek, Hrvatska University of Osijek School of Medicine, University Hospital Center Osijek, Osijek, Croatia

${ }^{2}$ Zavod za hitnu medicine Osijek, Osijek, Hrvatska 2Department of Emergency medicine Osijek, Osijek, Croatia

${ }^{3}$ Medicinski fakultet Sveučilišta u Osijeku, Osijek, Hrvatska ${ }^{3}$ University of Osijek School of Medicine, Osijek, Croatia

RECEIVED:

September 30, 2014

KLJUČNE RIJEČI: EKG visoke rezolucije, izoelektrična linija, dijastolička funkcija, mikrovoltažna promjenljivost. KEYWORDS: high resolution ECG, isoelectric line, diastolic function, microvoltage variability.

CITATION: Cardiol Croat. 2014;9(9-10):389.

*ADDRESS FOR CORRESPONDENCE: Klinički bolnički centar Osijek, Josipa Huttlera 4, 31000 Osijek, Croatia. / Phone: +385-91-2002-171 / E-mail: vbaraban@gmail.com

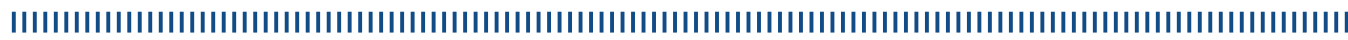

CILJ: Ovo istraživanje je temeljeno na teoretskom modelu srčane električne aktivnosti1. Cilj je bio utvrditi je li varijabilnost izoelektričnih segmenata (P-R, S-T i T-P) snimljenih pomoću triaksijalnog elektrokardiografa (EKG) visoke rezolucije u uzastopnim srčanim ciklusima pokazuje neke dobne i spolne različitosti. U ovom je radu poseban naglasak stavljan na analizu dijastoličke faze srčanog ciklusa, odnosno na T-P segment.

PACIJENTI I METODE: Ispitivanje je učinjeno kod ukupno 54 ispitanika (21 žena i 33 muškaraca); 27 mladih ispitanika (prosjek godina 21) i 27 starijih volontera (prosjek godina 53). Svakom ispitaniku snimljen je triaksijalni EKG visoke rezolucije (veličine uzorka $1 \mathrm{kHz}$ ) u trajanju od $200 \mathrm{sec}$, putem Biopac Student Lab. uređaja. Iz T-P intervala izdvojeno je 5 izoelektričnih segmenata, svaki trajanja $50 \mathrm{~ms}$, odabranih za analizu dijastoličke funkcije. Položaj svakog od tih segmenata je preciziran prema poziciji $\mathrm{R}$ vala. Za analizu izdvojenih segmenata korištena je Fourierova transformacija: A) u analizi promjenjivosti udaljenosti od svake XYZ točke - medijana oblaka segmenta (u mV); B) $u$ analizi promjenljivosti brzine prostornog pomaka između sukcesivnih milisekundi ( $\mathrm{mV} / \mathrm{ms}$ ).

REZULTATI: Metodom A potvrđene su razlike specifične za dob i spol tijekom dijastoličke faze srčanog ciklusa. Kod žena su izražene manje snage harmonika tijekom protodijastole, dok su viši harmonici bili jači tijekom teledijastole. Stariji ispitanici iskazali su više harmonike tijekom teledijastole. Metodom B potvrđene su dobne razlike u svih pet dijastoličkih izoelektričnih segmenata. Kako se nisu potvrdile razlike u ovisnosti o spolu, rezultati dobiveni ovom metodom sugeriraju da je mikrovotažna promjenljivost bila isključivo ovisna o dobi.

ZAKLJUČAK: Dobiveni rezultati se uklapaju u bazični teoretski model kojim se srčana aktivnost može opisati dinamičnim prijelazima između pojedinih stabilnih formi srčanog električnog polja tijekom cijelog srčanog ciklusa, kao i tijekom u ovom radu posebno analiziranih dijastoličkih segmenata.
AIM: This study was based on a theoretic model of heart electric activity. The aim was to determine whether variability of the high resolution three axially recorded isoelectric segments (P-R, S-T and T-P) in successive cardiac cycles show some age or gender specific features. In this paper a special emphasis was placed on the diastolic charging analysis i.e. separated T-P segments.

PATIENTS AND METHODS: A total of 54 volunteers were included in the study (21 female and 33 men); 27 younger (mean age 21 years) and 27 older volunteers (mean age 53 years). Three-axial high-resolution ECG (1 kHz sampling rate) of healthy subjects during 200 seconds, recorded by Biopac Students Lab. During T-P interval, five isoelectric segments (duration of each one: $50 \mathrm{~ms}$ ) were chosen for analysis of diastolic function and were then extracted due to their position from the $\mathrm{R}$ wave peak. Fourier analysis was done: A) Fourier of distances in $\mathrm{mV}$ between each XYZ point and the center of that segment; B) Fourier of distances in millivolts between successive milliseconds, in $\mathrm{mV} / \mathrm{ms}$.

RESULTS: Method A: Gender and age specific differences were found during the diastolic phase of the cycle. Women showed smaller harmonic powers during protodiastole while higher harmonics were stronger in telediastole. Older persons showed higher harmonics during telediastole Method B: Age dependent differences were found in all five diastolic isoelectric segments which represent the phase of diastolic charging. No gender specific differences suggest that this variability was purely age dependent.

CONCLUSIONS: These results fit well the initial theoretic model, the heart electric activity can be described as unbalanced transitions between stable configurations of the heart electric field during diastolic isoelectric segments.

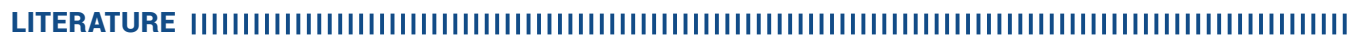
Kurbel S. A vector-free EKG interpretation with P, QRS \& T waves as unbalanced transitons between stable configurations of the heart electric field during P-R, S-T \& T-P segments. Theor Biol Med Model. 2014 Feb 10;11:10.

2. Narayanaswamy S. High resolution electrocardiography. Indian Pacing Electrophysiol J. 2002;2(2):50-6.

3. Jesus S. Rix H. High resolution EKG analysis by an aproved signal averaging method and comparison with a beat-to-beat approach. J Biomed Eng. 1988;10(19):25-32. 